\title{
Characterization of an RF- Driven Plasma Ion Source for Heavy Ion Fusion
}

\author{
G. Westenskow, R. P. Hall, E. Halaxa, J. W. Kwan
}

This article was submitted to: Particle Accelerator Conference 2003 Portland, Oregon, USA 05/12/2003 - 5/16/2003

\section{May 13, 2003}

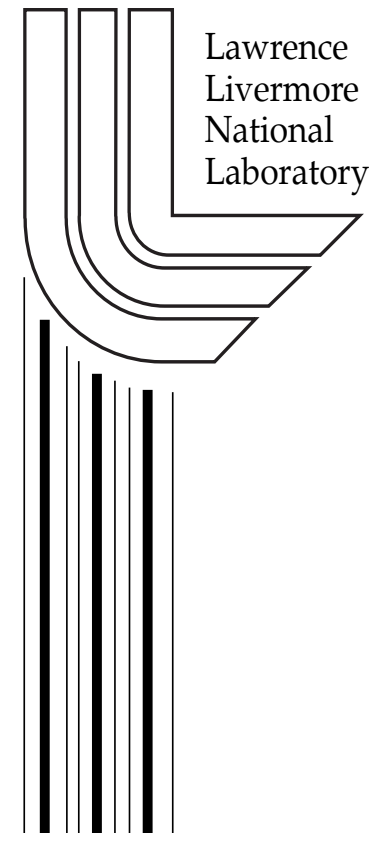




\section{DISCLAIMER}

This document was prepared as an account of work sponsored by an agency of the United States Government. Neither the United States Government nor the University of California nor any of their employees, makes any warranty, express or implied, or assumes any legal liability or responsibility for the accuracy, completeness, or usefulness of any information, apparatus, product, or process disclosed, or represents that its use would not infringe privately owned rights. Reference herein to any specific commercial product, process, or service by trade name, trademark, manufacturer, or otherwise, does not necessarily constitute or imply its endorsement, recommendation, or favoring by the United States Government or the University of California. The views and opinions of authors expressed herein do not necessarily state or reflect those of the United States Government or the University of California, and shall not be used for advertising or product endorsement purposes.

This is a preprint of a paper intended for publication in a journal or proceedings. Since changes may be made before publication, this preprint is made available with the understanding that it will not be cited or reproduced without the permission of the author.

This work was performed under the auspices of the United States Department of Energy by the University of California, Lawrence Livermore National Laboratory under contract No. W-7405-Eng-48.

This report has been reproduced directly from the best available copy.

Available electronically at http://www.doc.gov/bridge

Available for a processing fee to U.S. Department of Energy

And its contractors in paper from

U.S. Department of Energy

Office of Scientific and Technical Information

P.O. Box 62

Oak Ridge, TN 37831-0062

Telephone: (865) 576-8401

Facsimile: (865) 576-5728

E-mail: reports@adonis.osti.gov

Available for the sale to the public from

U.S. Department of Commerce

National Technical Information Service

5285 Port Royal Road

Springfield, VA 22161

Telephone: (800) 553-6847

Facsimile: (703) 605-6900

E-mail: orders@ntis.fedworld.gov

Online ordering: http://www.ntis.gov/ordering.htm

Or

Lawrence Livermore National Laboratory

Technical Information Department's Digital Library

http://www.llnl.gov/tid/Library.html 


\title{
CHARACTERIZATION OF AN RF-DRIVEN PLASMA ION SOURCE FOR HEAVY ION FUSION*
}

\author{
G. Westenskow, R. P. Hall, E. Halaxa, Lawrence Livermore National Laboratory; \\ J. W. Kwan, Lawrence Berkeley National Laboratory
}

\section{Abstract}

We are testing a high-current-density high-brightness Argon-Ion Source for Heavy Ion Fusion applications. The $100-\mathrm{kV} 20-\mu$ s source has produced up to $5 \mathrm{~mA}$ of $\mathrm{Ar}^{+}$in a single beamlet. The extraction current density is $100 \mathrm{~mA} / \mathrm{cm}^{2}$. We have measured the emittance of the beamlet, and the fraction of $\mathrm{Ar}^{++}$ions under several operating conditions. We present measurements of the extracted current density as a function of RF power and gas pressure $(\sim 2 \mathrm{mT})$, current density uniformity, and energy dispersion (due to charge exchange). We are testing a $80-\mathrm{kV}$ 61-hole multi-beamlet array that will produce a total current $>200 \mathrm{~mA}$. In the current experiments the beamlets are not merged into a single beam. A $500-\mathrm{kV}$ experiment where the beamlets will be merged to a produce 0.5 -A beam is being planned.

\section{BACKGROUND}

Following a proposal that the usual limits on brightness for compact ion-beam sources used in Heavy Ion Fusion can be circumvented by using a multi-beamlet injector [1] we have started an experimental program to examine practical issues. The final source envisioned will start with $\sim 1005-\mathrm{mA}$ beamlets across a 100-kV gap. The beamlets will be focused by Einzel Lens while their energy is increased to about $1.6 \mathrm{MeV}$. The beamlets are then merged to produce a 0.5 -A beam with a normalized emittance below $1 \pi$-mm-mrad.

Beyond providing a low-temperature source that can provide ion emission densities of $\sim 100 \mathrm{~mA} / \mathrm{cm}^{2}$ [2], the main physics issues involved in the multi-beamlet approach are emittance growth and envelope matching in the merging process. In computer simulations, if the initial emittance is in the range of measured values, the final emittance increases only weakly with the initial emittance of the individual beamlets.

We have available three test stands for developing the concept. The first has a small chamber with voltages below $50 \mathrm{kV}$. The second has increased diagnostics and $100 \mathrm{kV}$. The third larger system is capable of $500 \mathrm{kV}$ with a $20 \mu$ sec pulse [3].

We will first describe the characteristics of a single beamlet. We will then give early results from a "61beamlet" array. During the next year we have a series of planned experiments that move the design closer to a source that could be used in the driver.

*This work has been performed under the auspices of the US DOE by UC-LBNL under contract DE-AC0376SF00098 and by UC-LLNL under contract W-7405ENG-48, for the Heavy Ion Fusion Virtual National Laboratory. Email: westenskow1@1lnl.gov

\section{STUDYING INDIVUDUAL BEAMLETS}

We are using an $\mathrm{rf}$ plasma source to produce the Argon ions. The plasma chamber is $33 \mathrm{~cm}$ in diameter with multicusp permanent magnets to confine plasma. RF power $(\sim 11 \mathrm{MHz},>10 \mathrm{~kW})$ is applied to the source via a 2-turn, 11-cm diameter antenna inside the chamber for producing beam pulses of $20 \mu \mathrm{s}$ at up to $10 \mathrm{~Hz}$. We have shown that we can extract $100 \mathrm{~mA} / \mathrm{cm}^{2}$ from the chamber. Optimum performance has been with $\sim 2 \mathrm{mT}$ gas in the plasma chamber.

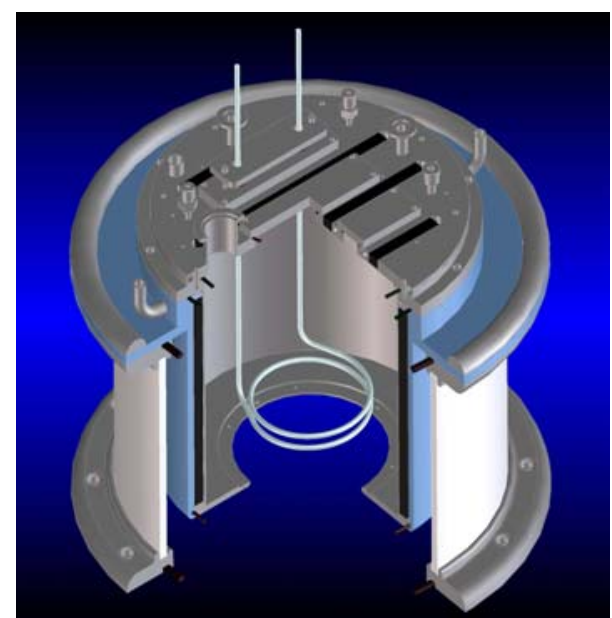

Fig. 1: RF plasma source used in the experiments.

\section{Beam Current}

Our first step was to characterize the current in a single beamlet from the rf plasma source (see Fig. 2).

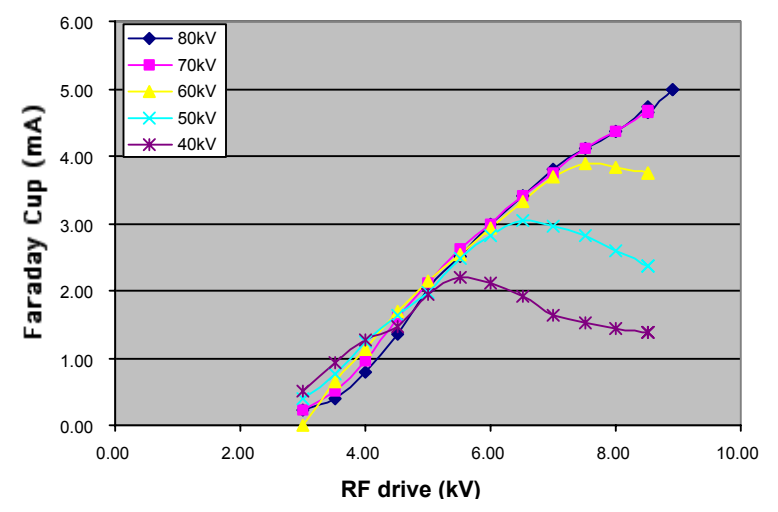

Fig. 2: Extracted current in a single beamlet at $2 \mathrm{mT}$ source pressure. The aperture was $2.5 \mathrm{~mm}$ diameter. The curves are different gap potentials. The " $10 \mathrm{kV}$ RF drive" is about $12 \mathrm{~kW}$ of power from the rf source. 


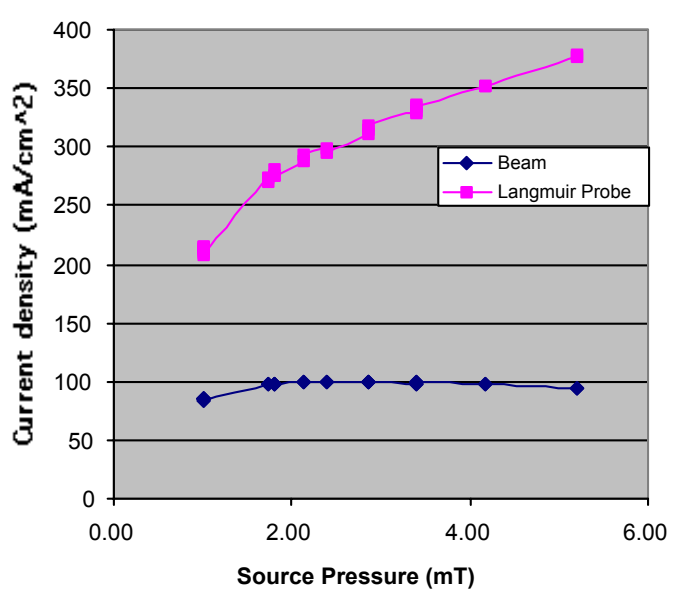

Fig. 3: Effect of source pressure on extracted current and the ion density in the chamber. Gap voltage was $80 \mathrm{kV}$ and the RF drive was $8.5 \mathrm{kV}$.

As shown in Fig. 3 increasing the source pressure above $2 \mathrm{mT}$ continued to increase the ion density in the chamber, but did not yield higher extracted currents from the gap. Increasing the source pressure increases charge exchange in the gap.

\section{Charge state and charge exchange}

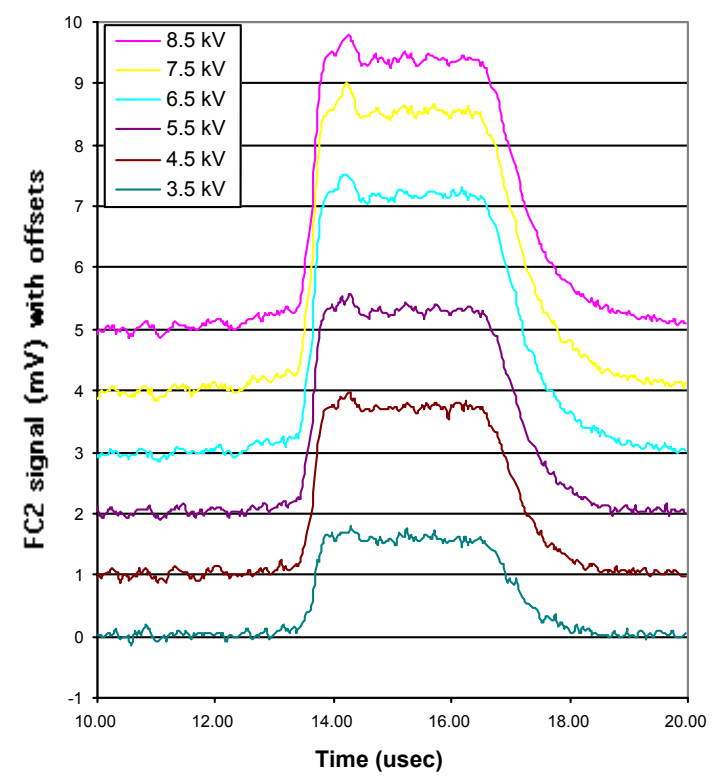

Fig. 4: Arrival time of ions at the back Faraday Cup.

A crude measurement of the ionization state was done by using time-of-flight information. We have a 1.5 meter drift section between pulsed dipole plates and a Faraday Cup. Since there was no focusing, the beam diameter at the cup was larger than it's acceptance. We switched the beam into the Faraday Cup during the center of the pulse. $\mathrm{The}{ }^{++}$ions will have higher momentum, and the front edge of the pulse will arrive at the Faraday Cup before the $\mathrm{Ar}^{+}$ions. At drive powers higher than $5 \mathrm{~kW}$, we did see a "front step" in the ion current at the cup (see Fig. 4). We estimated that less than $5 \%$ of the extracted ions were in the $\mathrm{Ar}^{++}$state.

An early concern was that collisions between the extracted ions and the background gas would yield an excessive amount of charge exchange. The newly created ions would leave the gap with lower energies and different transverse motion. Using the dipole plates as an "energy analyzer" we looked for a shift in the profile at the slit cup. We even increased the background gas pressure in the gap to enhance the effect. Our preliminary conclusion is that the energy spread is small. It is conceivable that most of the ions that undergo collisions do not reach the Faraday Cup. Further experiments are planned to improve our ability to resolve energy spread.

\section{Emittance}

We used a narrow slit and slit cup to examine the $\mathrm{x}-\mathrm{x}$ ' phase space of a beamlet. An example is shown in Fig. 5.

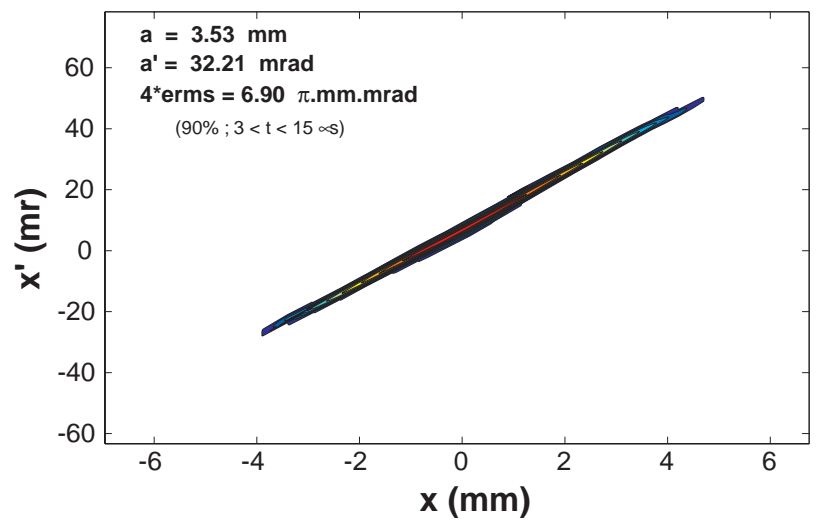

Fig. 5: Phase space of a beamlet $12 \mathrm{~cm}$ from the extraction plate. Operation at $80 \mathrm{kV}, 2.1 \mathrm{mT}$ source pressure, $6.5 \mathrm{kV}$ RF drive. Cut taken at $90 \%$ of the peak valve. Early values removed to reduce noise from the spark gaps.

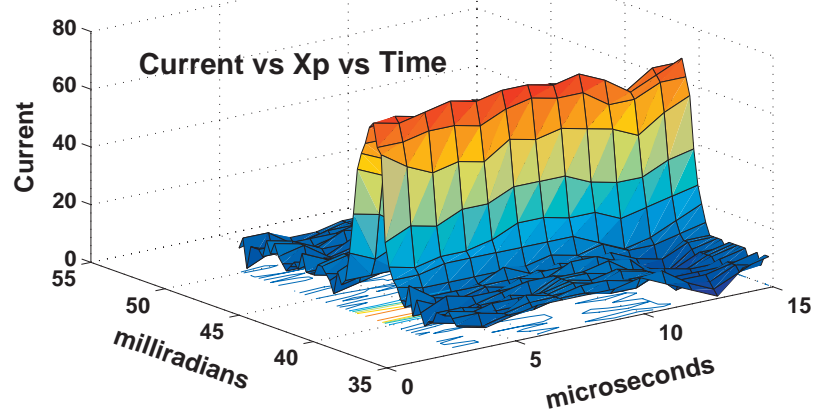

Fig. 6: The current at the slit cup verses angle from the slit as a function of time. Same parameters as in Fig. 5.

The beam parameters were stable over the 3 to $15 \mu \mathrm{s}$ period as shown in Fig. 6. The deviation at $12 \mu \mathrm{s}$ is believed to be from a problem with the diagnostics. The normalized emittance for the beamlet was $\sim 0.015$ $\pi \cdot \mathrm{mm} \cdot \mathrm{mrad}$. 


\section{CURRENT EXPERIMENTS}

We are presently investigating a multi-beamlet extraction array. The 1.6-cm gap is held with three highgradient insulators. The bottom beam-forming plate in Fig. 7 has Pierce Cones for each of the beamlets. The apertures in the bottom plate are $2.2 \mathrm{~mm}$ diameter. The holes in the top plate are $4.0 \mathrm{~mm}$ diameter. Figure 8 shows the change in the opacity of a kapton sheet hit with $50-\mathrm{kV}$ $20-\mu$ s beamlets from the array. The kapton sheet was $2 \mathrm{~cm}$ from the extraction plate. Figure 9 is a lineout of the image shown in Fig. 8.

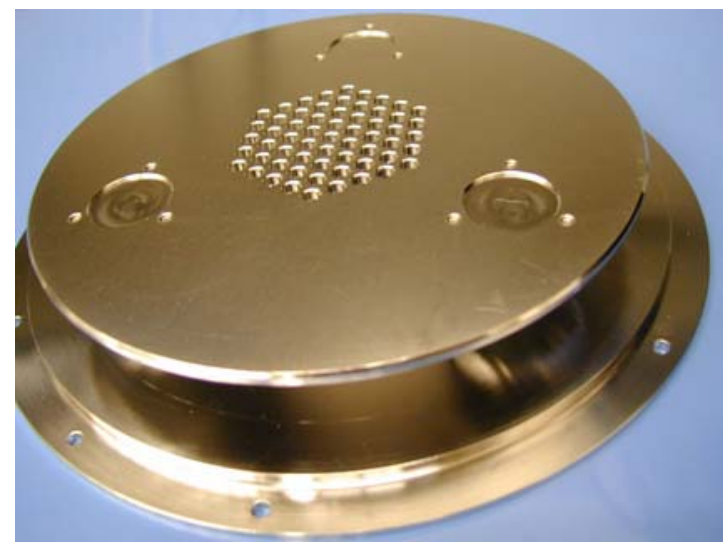

Fig. 7: Extraction plate for the 61-beamlet array.

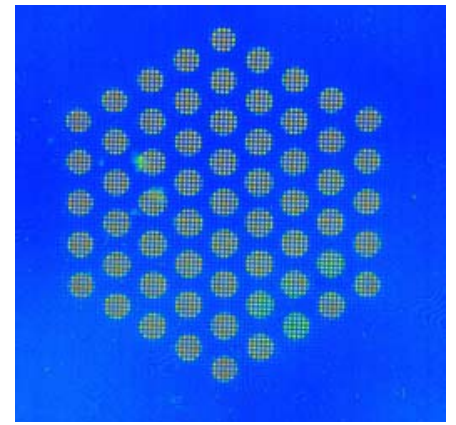

Figure 8. Image produced by ions hitting a Kapton sheet.

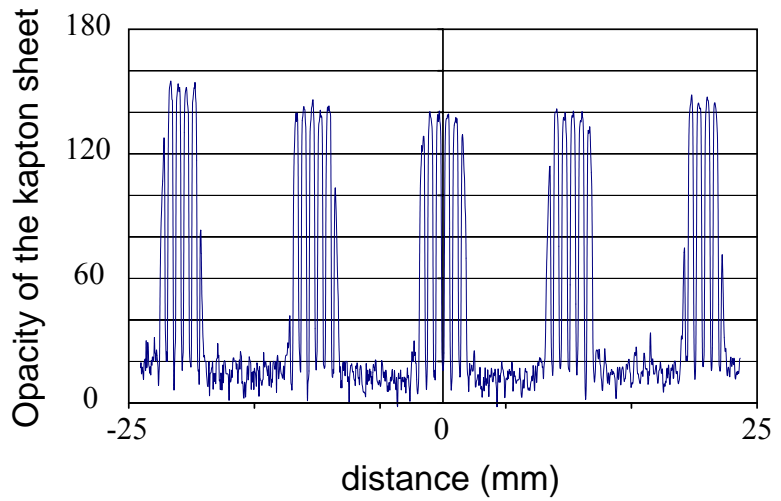

Fig. 9: Line out of the above image taken at the first row of complete beamlets. The fine structure is from a metal screen placed in front of the Kapton sheet to stop ion charge buildup.

\section{NEXT STEPS}

After further characterization of the beamlets, our next step will be to add Einzel Lens to the present configuration (shown in Fig. 10). In latter versions the lens will be used to boost the energy of the beamlets. We plan to separate the lens with high-gradient insulators. The separation of the lens is about $1 \mathrm{~cm}$.

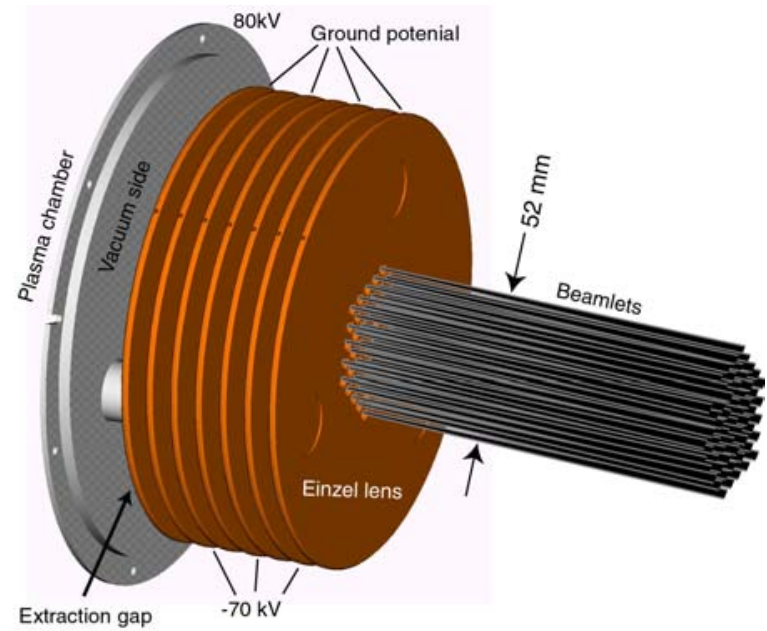

Fig. 10: Next experiment with extraction gap and Einzel Lens.

Merging of the beamlets will not be done at this stage because the perveance is too high. Also, minimizing the final transverse phase space will require curved plates for the Einzel Lens. We are designing an experiment with the extraction gap at $\sim 100 \mathrm{kV}$ with post acceleration up to $500 \mathrm{keV}$.

\section{ACKNOWLEGEMENT}

We would like to thank Gary Freeze and Will Waldron for their assistance with the experiments. Also wish to thank Larry Ahle for his preparation work on the experiment.

\section{REFERENCES}

[1] D.P. Grote, E. Henestroza, J.W. Kwan, PRST Accelerators and Beams, Vol. 6, 014202 (2003).

[2] L. Ahle, et al., R. of Sc. Inst., Vol. 73 \#2, p. 1039, (2002)

[3] L. Ahle, D.P. Grote, J.W. Kwan, Laser and Particle Beams, Vol. 20 (2002). 